\title{
Management of Tags and Tag-Related Technical Information in Small and Large Scale Modifications: An Application for a Drilling Rig
}

\author{
Jawad Raza $^{1}$ and R.M. Chandima Ratnayake ${ }^{2}$ \\ ${ }^{1}$ Apply Sørco, Sandnes, Norway \\ ${ }^{2}$ University of Stavanger, Stavanger, Norway \\ Jawad.raza@applysorco.no, chandima.ratnayake@uis.no
}

\begin{abstract}
Considerable amount of Oil and Gas (O\&G) production and process installations operating in the North Sea are getting aged and requiring continuous modifications. Nature of such contractual jobs is relatively short term with demanding deliverables. Hence, the engineering contractors require excellent coordination and seamless communication during all phases of a project. For any contractor/supplier, it is of utmost importance to ensure that equipment related technical information is made available at the right time to avoid any unexpected project delays. Experience shows that poor coordination among project participants can result in failing to comply with regulatory and governing requirements. Also, there are other challenges to managing tags, databases and tag history as well as keeping technical information integrity. This manuscript illustrates role of a tag management system developed by an engineering contractor company which provides services to operators in NCS. The particular system is developed and customized to meet a drilling rig client's specification.
\end{abstract}

Keywords: Tag Manager, Technical information management, Maintenance and Modification, Life Cycle Information (LCI), Project Execution Model (PEM), Norwegian rig market.

\section{Introduction}

Recent findings reveal that the Maintenance and Modification (M\&M) of the assets used within the Oil and Gas $(\mathrm{O} \& \mathrm{G})$ drilling discipline are facing numerous unique challenges [CCR, 2011; Staff, 2012]. It is undoubtedly quite significant to have a system to manage tags and their corresponding Life Cycle Information (LCI) in order to meet the project targets. The offshore drilling industry (i.e. rig market) is considered as chronically cyclical and extremely capital intensive. For instance, once a rig is built, the owner is strongly motivated to secure work at any reasonable cost, as the expenses related to maintain an idle rig is extremely high. This creates a very competitive pricing environment for even modest amount of rig shut down to carry out M\&M [Simmons, 2002] whilst compensating interests between continuation of drilling operations and shutting down for maintenance. For instance, "BP was not obliged to pay for time in excess of 24 hours each month spent on certain repairs on 
"Deepwater Horizon". As a result, drilling priorities took precedence over planned maintenance. For instance, "the Deepwater Horizon had never been to dry dock for shore-based repairs in the nine years since it had been built" [CCR, 2011]. Consequently, a leading O\&G operator company, BP, was almost brought to bankruptcy due to Macondo well blowout in the Gulf of Mexico [Ratnayake et al., 2011]. Therefore, it is vital to have an approach to enhance and optimize small and large scale M\&M projects on rigs. Hence, this manuscript elaborates a system developed for management of tags and tag-related technical information in modifications that supposed to be carried out on a drilling rig.

\section{Background}

A recent survey by Norwegian Petroleum Authority (PSA) reveals that about 50 percent of all existing installations in the North Sea are approaching their design life [MPE, 2010]. Hence, M\&M plays a significant role for continue operation on these installations in a safe manner. This resulted to award giant M\&M (Maintenance \& Modification) and EPCIC (Engineering, Procurement, Construction, Installation \& Commissioning) contracts in past few years to the contractor companies from the operator companies [ON, 2012]. Successful execution and completion of small and large scale projects relies on factors such as technical information, competencies, teamwork, tag management, communication and quality assurance, etc. It is also important that all the vital elements of a project to be coordinated for meeting the deliverables and milestones. Figure 1 shows key elements in M\&M and EPCIC project execution.

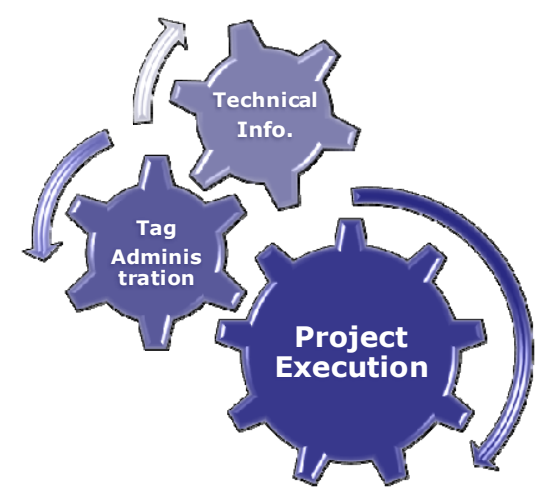

Fig. 1. Project execution in M\&M and EPCIC

Based on the scale of a modification project, there may be several parties, tools and complex work processes involved in planning and execution. This demand for tools to communicate and manage project deliverables as well as retain the integrity of technical information through all the phases of the project. Failing to establish a seamless communication may result in failing to comply with the Norwegian and company specific regulatory requirements. 
In any $\mathrm{M} \& \mathrm{M}$ project, administration of equipment and equipment-related information provides basis for design, installation, maintenance planning, scheduling and spare parts evaluation, etc. All the equipments and components in a M\&M project are designated as particular code which is named as a 'tag number' or simply a 'tag'. Basically the 'tag' or 'tag number' is a unique code that defines the functional location and function of a physical component or equipment in the main facility [NORSOK Z-DP-002, 1996]. The 'tag number' assigned to each equipment is based on Company's Engineering Numbering System (ENS) guidelines in compliance with applicable equipment coding standards.

Managing documentation integrity in small and large-scale modification projects has always been a challenge for many Oil and Gas $(O \& G)$ organizations and rig market. This can be even more challenging for those organizations that are lacking necessary resources and appropriate tools. A basis study conducted by Norwegian Oil Directorate [OD, 1998] revealed that many organizations struggle with dynamic updating and validating of the technical documentation. Flow of equipment related technical information and coordination among all involved parties is a must for successful execution of any modification project.

Figure 2 shows the role of technical information in managing technical information integrity in modification projects.

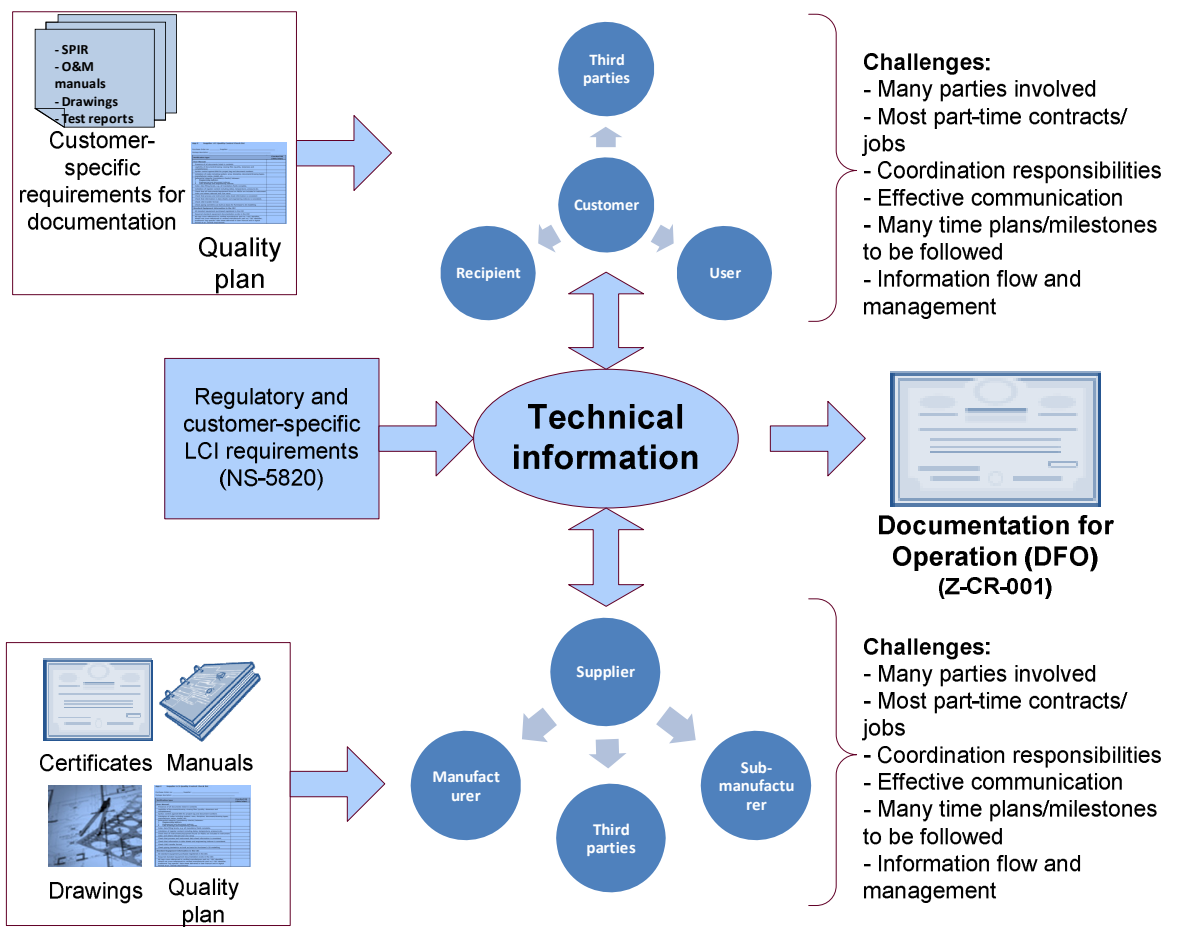

Fig. 2. Flow of technical information in M\&M projects 
Equipment/tag related technical information may include Data for HSE, Piping \& Identification Diagrams (P\&IDs), data sheets, drawings, O\&M manuals, single line diagrams, EX-certifications, System control diagrams etc. Customers define criteria for the requirements in accordance with applicable LCI regulations and standards.

The Life Cycle Information (LCI) can be defined as:

"Information required by Company for engineering, preparation for operation, start-up, operation, maintenance, repair, modification and decommissioning of a plant/installation" [NORSOK NS5820, 1994].

LCI include both information submitted to the Company and/or retained by the Supplier on behalf of the Company. LCI includes what has previously been termed as Documentation For Operation (DFO). Updates of LCI information may be required with any modifications.

Such information is usually in manuals or datasheets provided by the supplier (usually in pdf or Excel format). The required information is delivered from supplier together with a quality plan that is mutually agreed upon with the customer's requirements. Once all the requirements are fulfilled, the information is released for a DFO.

In general, all such information is to be made available well before the project reaches its completion phase. The flow of this information should be ensured based on the Company-specific PEM. Failing to fulfill such requirements in-time may affect the overall project progress leading to inadequate equipment-/tag-information in the tag database (Referred to as master register in this context). Master register keeps information of all tags with a reference to the relevant technical information. This database must be accurate and updated at all times as this usually forms the basis for Computerized Maintenance Management System (CMMS). Any incomplete or wrong information in the master register can affect maintenance management of the asset. Such nonconformities in the master register can further affect quality in terms of double registration of tags, poor administration, lack of historical track of new and existing tags and inadequate technical information. Experience within Norwegian O\&G industry reveals that most projects, both large and small scale, suffer due to inadequacy and lack of technical documentation, therefore many companies fail to comply with corporate LCI requirements and NORSOK requirements.

In order to comply with applicable regulatory and standard requirements to manage all tags and tag-related technical information and to keep the information integrity intact in an M\&M project, Apply Sørco developed a web-based tag management system, named as TAG Manager. TAG Manager is developed in a dynamic web-based environment (i.e. ASP.Net) and provides easy access to all users to manage tags for modification and to follow up tag-related technical information. The System also maintains a log database for any operations being performed in the System. It keeps interactive tag status, manages technical information and provides flexible audit trail.

Offshore O\&G industry involves high risk and therefore Norwegian Petroleum Authorities have large focus on safe and effective maintenance of the asset. An overview of relevant legislation and standards for NCS are summarized in the next section. 


\section{Norwegian Legislation and Standardization}

Norwegian PSA has defined set of central regulations for offshore and onshore activities. These include regulations for framework HSE, management, facilities, activities and technical \& operational regulations [PSA, 2011]. All petroleum related activities conducted onshore and offshore on the North Sea are obliged to follow governing regulations and other applicable standard requirements.

In M\&M and EPCIC projects, both contractor/supplier and operator must align their activities within defined premises of the Norwegian regulations. Some of the applicable regulations and significant standard requirements related to M\&M projects are summarized here:

\subsection{Management Regulations}

Ref. § 13 Work processes: [PSA, 2011]

- $\quad$ The responsible party shall ensure that the work processes and the resulting products fulfil the requirements related to health, safety and the environment.

- Work processes and associated interfaces of significance to health, safety and the environment shall be described. The level of detail in the description shall be adapted to the importance of the process for health, safety and the environment.

Ref. § 15 Information: [PSA, 2011]

- $\quad$ The responsible party shall identify the information necessary to plan and carry out the activities and improve health, safety and the environment.

- It shall be ensured that the necessary information is acquired, processed and communicated to relevant users at the right time.

- Information and communication systems shall be established that safeguard the need for acquiring, processing and communicating data and information.

\subsection{The Framework Regulations}

Ref. §17 Management system: [PSA, 2011]

- $\quad$ The responsible party shall establish, follow up and further develop a management system designed to ensure compliance with requirements in the health, safety and environment legislation.

- $\quad$ The licensee and owner of an onshore facility shall establish, follow up and further develop a management system to ensure compliance with requirements in the health, safety and environment legislation directed toward licensees and owners of onshore facilities. 


\subsection{NORSOK Standard Requirements}

The purpose of NORSOK standards is to reduce implementation time and costs for construction and operation of petroleum installations on the NCS. These provide guidelines and best practices that ensures a safe and cost-efficient environment for activities related to offshore and onshore. For instance NORSOK NS5820 (1994) provides a framework for the extent and presentation of suitable documentation for equipment deliveries. The standard is used for all types of equipments, from standard products to package equipment. NORSOK Z-001(1996), defines the extent of technical information which shall be available for use in the operational phase. It emphasizes that:

- All information shall have As-built status and be available on electronic media.

NORSOK Z-003 (1996) provides requirements for electronic storage and interchange of technical information and data between all parties and during all phases of an offshore installation's life cycle. Among other requirements, it includes:

- Enabling cost-effective electronic information interchange between all parties. Electronic information shall be accepted as an original

- Ensuring that electronic information at any time has only one source and responsible owner.

- Contributing to the production and use of correct data of a known quality throughout the total life cycle.

- Ensuing that information structures, data bases and systems that enable concurrent engineering shall be used (i.e. maximize information sharing).

\section{Gaps and Practical Challenges}

Independent of the scale of M\&M projects, all involved parties need to perform the job in a safe and cost efficient manner under the applicable regulatory and companyspecific requirements. This requires seamless communication and deliverables as defined in the Company's PEM. Based on vast experience from M\&M and EPCIC project execution, extensive manual efforts are required to track and follow up technical documents, to track any missing or inadequate information, coordinating other disciplines (LCI, maintenance etc.). Figure 3 indicates structure of LCI requirements that are defined by the customer in line with applicable regulatory and governing standard requirements. 

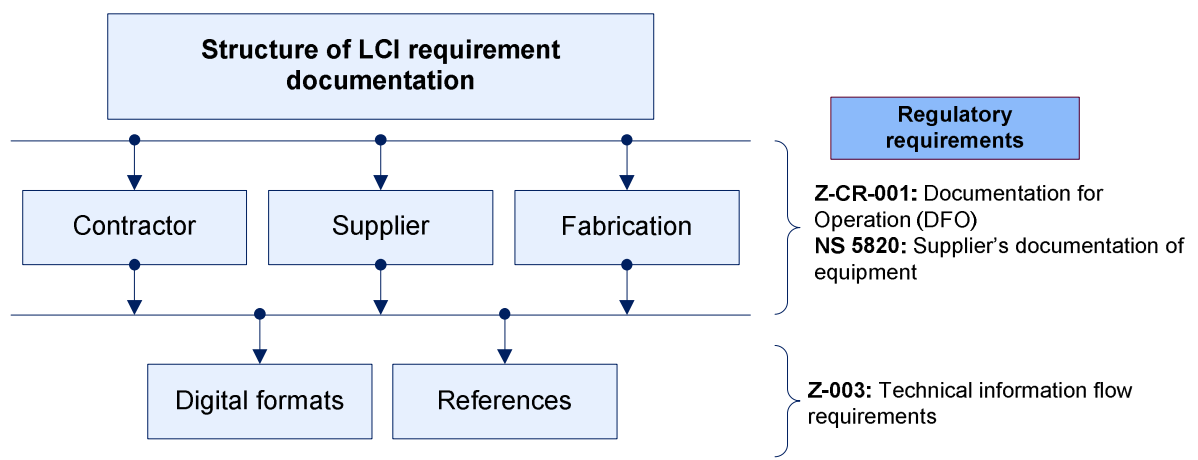

Fig. 3. Structure of LCI requirement documentation

Based on experience from large-scale modification projects identified gaps and challenges are summarized here with respect to applicable regulatory requirements and standard practices.

Practical challenges associated with $M \& M$ project execution include:

1. To establish a common platform for effective communication and coordination as many parties involved in a PEM.

2. To effectively manage tags and related technical information during a PEM

3. Local and global standardization of tag management process

4. To fulfill LCI requirement

5. To define a quality plan between customer and supplier to ensure high quality of project deliverables

6. To receive all necessary technical documentation on the right time during a PEM

7. To actively follow-up with the supplier in different phases of a PEM execution

8. To maintain a tidy-up master register with up-to-date status of tags highlighting modified/demolished/obsolete tags etc.

9. To maintain information of non-maintainable tags such as cables and pipeline information

10. To manage and administer dynamic records and history of all tag(s) in the database

11. To manage updated tag-related technical information in the database

In order to comply with applicable regulatory requirements and standards, robust technological solutions are needed.

In order to meet these challenges, TAG Manager offers an opportunity to manage tags and flow of technical information in PEM thereby ensuring safe and costeffective process. Main features and capabilities of the Apply Sørco's TAG Manager are summarized in the next section. 


\section{TAG Manager}

TAG Manager is developed by Apply Sørco in line with applicable regulatory requirements and norms. It offers great flexibility in managing tags and tag-related technical information in modification projects. It is developed to meet the requirements for large- and small-scale modification projects.

Main features of TAG Manager System are:

- Setting up a work process for safe and efficient management of tags and tagrelated technical information in compliance to client's PEM (In compliance with $\$ 13$ Work processes)

- Automated flow of information of tags and dynamic reference of tag-related technical information, according to applicable LCI and standard requirements, to and from the vendor in-line with PEM phases (In compliance with \$15 Information)

- Dynamic update of tag-related technical information (In compliance with NORSOK standard requirements)

- Minimum human efforts required to reserve new tags for modifications (In compliance with gaps and challenges item 2)

- Update of tag status in compliance to client's PEM defined milestones (In compliance with NORSOK standard requirements)

- Automatic update of master tag-register with relevant technical information according to applicable LCI requirements (In compliance with NORSOK standard requirements)

- Automatic deletion of any "reserved" tags so that these are available for reuse (In compliance with gaps and challenges item 10)

- Keep history of all tags in a manner that there are minimum possible unused tags left in the master tag-register. (In compliance with gaps and challenges item 8)

- Helps standardizing (both local and global) of tag management process on many installations

- Helps keeping database clean, updated and free from unused/obsolete tags (In compliance with NORSOK standard requirements)

- Multiple levels of user access including read-only, write and administrator level, ensuring the integrity of the tag database (In compliance with § 15 Information).

- Flexible report generator feature, keeping logs of users and the work history etc.

- User friendly interface with extensive database search capabilities

- Easy customization to any special requirements of the client

- Flexible to communicate and integrate with other management systems 
- A common mail box for keeping all communication to-and-from the customer and supplier(s)

- Integrated module capabilities including tag and functional hierarchy and criticality evaluation

Figure 4 shows role of TAG Manager with respect to a standard PEM.

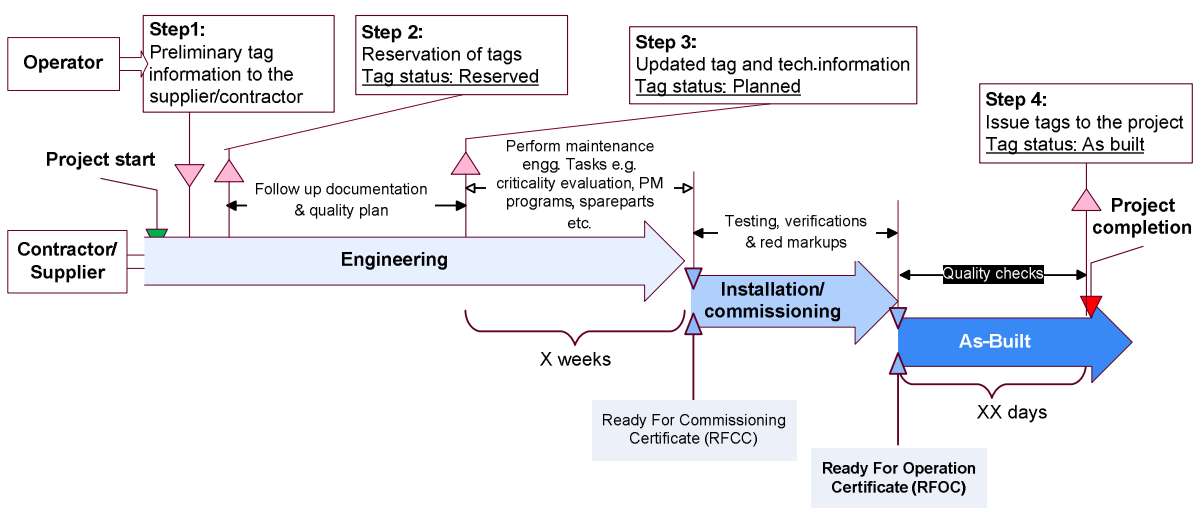

Fig. 4. TAG Manager System integrated with modification project execution model

TAG Manager is Apply Sørco’s product which is customized to meet the customer-specific. Customization is performed in three steps as shown in figure 5.



Fig. 5. Customization of TAG Manager for the client 
All databases and relevant existing tags and tag-related technical information need to be imported in form of a large tag database. In this phase, the opportunities to integrate TAG Manager with other management system with the client are discussed. Excel spreadsheets for different tag categories are also prepared as a part of the process. This is further customized to integrate with client's PEM. All tag formats are coded and programmed in the System.

To align TAG Manager with PEM, it is recommended to start using TAG Manager System immediately with start of modification project. Figure 6 shows screen shot of start screen that includes configuring project, establishing project number and Purchase Order (PO) as well as distributing user-permissions to those involved in the project. Project responsible/manager is responsible for establishing necessary project information and distributing necessary accesses to project team members.

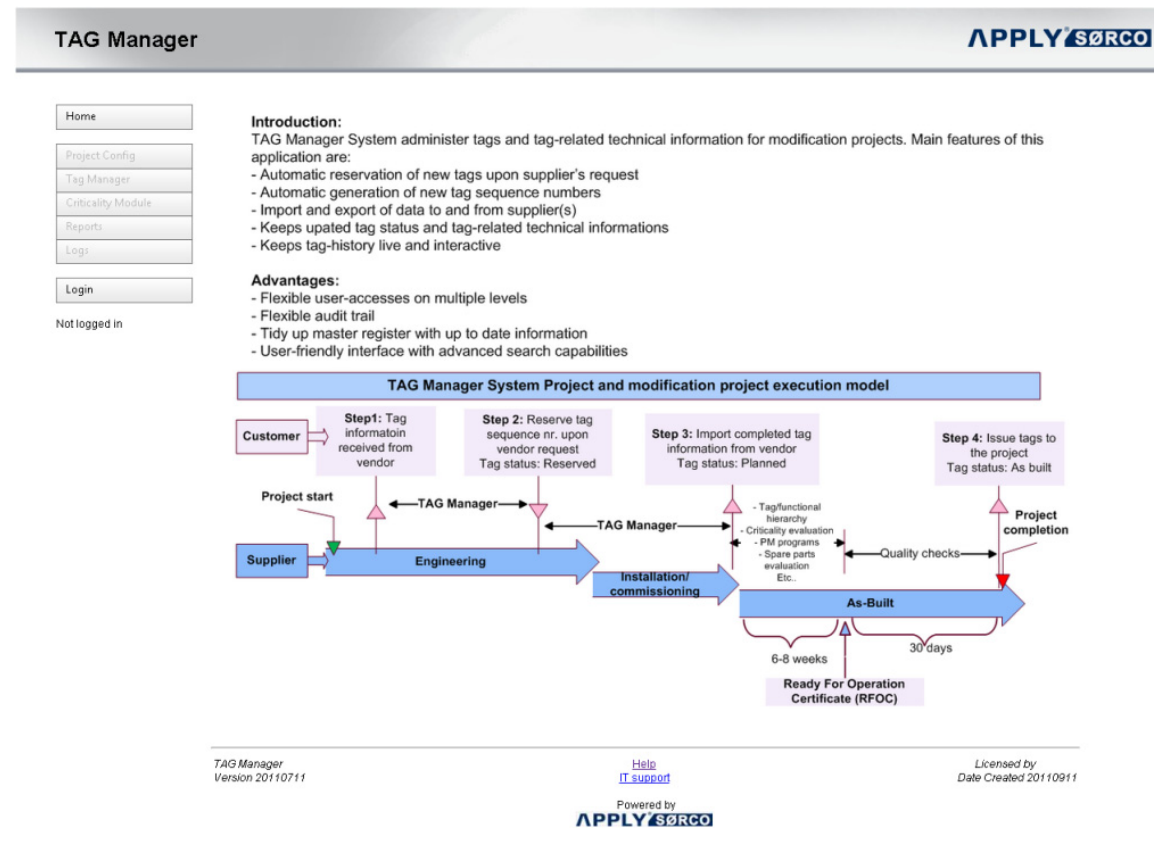

Fig. 6. Screen shot of TAG Manager System

TAG Manager specifies role of company (customer) and the vendor (supplier) in successful execution of modification project.

In operation, TAG Manager is based on 5 simple functional steps. During each step an effective coordination is required from all involved parties (e.g. project/contract responsible, discipline lead, LCI coordinator and any involved $3^{\text {rd }}$ parties).

Step 1: Sending request to supplier/contractor

TAG Manager has capabilities to send necessary documentations directly to the supplier. The requested information from supplier is according to regulatory LCI requirements and customer's governing documents. The documentation is part of the 
delivery from supplier and the extent of documentation is limited to that strictly required by the customer.

\section{Step 2: Reservation of tags}

Upon supplier's request, the number of required tag(s) are reserved with assigned sequence numbers based on availability in the master tag-register. This is performed automatic with minimum human intervention. TAG Manager has the capabilities to search for available sequence number and reserving tags for the project. Once these sequence numbers are generated these are issued back to supplier to provide required information for each type of equipment.

Step 3: Updating tag status during PEM execution

As the project approaches completion of the engineering phase, all tags received from the supplier with "planned" status. Supplier can leave any unused tags with "reserved" status. The updated information is automatically imported in TAG Manager and is kept in the TAG Manager database. Relevant discipline has the responsibility to ensure that all the right information is being supplied by the supplier prior to proceeding ahead with project.

Step 4: Revised and demolished tags

TAG Manager has the ability to handle different status of tags, such as those have been re-used by the project. Upon supplier request, these are flagged as "demolished", "deleted" or "revised" tags. TAG Manager flags each tag with relevant status offering historical overview of any such tags. No tag is physically deleted from the System, all such tags are kept in the database for historical purposes.

Step 5: Completion of a project

All planned tags, including those with "revised" and "demolished" tags are to be evaluated for criticality, spare parts and preventive maintenance activities. All of these updates should be completed in a given time frame that starts prior to mechanical completion. Upon successful completion, all planned tags are flagged as "Asbuilt" and ready to be issued for the project.

A quality control of all tags with respect to tag description and necessary information is performed prior to handing over to the project. Immediately when these tags are handed-over, any tags with "reserved" status are deleted and removed from the tag database. This is performed automatically so that their sequence number is ready for re-use for other projects. This minimizes any unnecessary loop-holes in numbering of the tags.

\section{Reports and User-Logs}

TAG Manager System keeps predefined reporting features for ease of generating reports for review/audit purposes. User logs are automatically generated and available as per needs lists all major actions performed by different users. 


\section{Discussions and Conclusions}

In order to ensure successful M\&M project execution, the TAG Manager offers great flexibility and interactivity to align with regulatory requirements. Effective integration of the System with PEM can significantly enhance the efficiency and profitability of the whole process of managing tags and tag-related technical information. Based on scale and complexity of modification projects, one of the key challenges is to manage and track modified equipments (tags) and relevant technical information as the project progresses. TAG Manager provides a systematic solution to manage tags and tag-related information integrity in M\&M project execution. Some of the recommended good practices in using TAG Manager are summarized as follows:

- Start of communication of project requirements and milestones as early in project startup phase among involved project team(s)/member(s) and TAG Manager users/administrators.

- Integration of TAG Manager System with project plan/milestones in the earliest engineering phase to assist ensure seamless communication between customer and supplier(s) as early in start of a modification project

- Use of TAG Manager for tag and tag-related technical information management forming a robust network for communication in a project

- Perform necessary quality control of deliverables from supplier according to mutually agreed quality plan among customer and supplier(s)

- Ensure necessary training for all participants including for customer and contractor/supplier and mutual understanding and agreement of deliverables and deadlines as defined in PEM

- It is necessary to define an interface/work process to coordinate with other disciplines via TAG Manager to meet LCI and project specific requirements

- Involvement of all parties through TAG Manager in all PEM phases, starting from project start-up to project handover

Acknowledgements. Authors would like to thank the specialist from Apply Sørco for technical input and fruitful discussions in writing the paper.

\section{References}

CCR, Chief Counsels Report: Chapter 4.10: Maintenance, pp. 221-224 (2011), http://www.oilspillcommission.gov/chief-counsels-report (accessed on July 18, 2011)

Ministry of Petroleum and Energy (2010), http: / /www.regjeringen.no (accessed May 24, 2012)

NORSOK Z-003, Technical information flow requirements (1996), http: / /www. standard. no (accessed on May 05, 2011) 
NORSOK Z-001, Document For Operation (DFO) (1996), http: //www. standard.no (accessed on July 03, 2011)

NORSOK NS5820, Supplier's documentation of equipment (1994), http: / / www . standard. no (accessed on July 05, 2011)

NORSOK Z-DP-002, Design principles; coding system (1996), http: / /www. standard. no (accessed on June 12, 2011)

OD, Basisstudie vedlikeholdsstyring Metode for egenvurdering av vedlikeholdsstyring. Olje Directorat (1998)

ON, Offshore News (2012), http: //offshore.no/nyheter/Nyhetskategori.aspx?qcat=9 (accessed May 17, 2012)

PSA, Petroleum Safety Authority regulations (2011), http: / / www.ptil.no/regulations (accessed on July 17, 2011)

Ratnayake, R.M.C., Samarakoon, S.M.S.M.K., Gudmestad, O.T.: Integrity Management for Sustainable Asset Operations: The Role of Qualification Process. In: Proceedings of the 24th International Congress on Condition Monitoring and Diagnostics Engineering Management (2011) ISBN 0-9541307-2-3

Simmons, M.R.: Offshore rig market could be on verge of recovery. Drilling Contractor (May/June 2002)

Staff, C.: Petroleum Safety Authority Flags Transocean Citing "Serious Breaches" (2012), http: / /gcaptain.com/petroleum-safety-authority-flags / ? 45641 (accessed on May 25, 2012) 